Introduction to the

ERos

sioux Falls, South Dakota

by L. A. Braconnier and P. J. Wiepking

Products and Services

The EROS Data Center is a part of the Earth
Resources Observation Systems (EROS) Of-

ice of the Department of the Interior and is

It is the national clearinghouse forvey.
Ithe proc-
essing and dissemination of spacecraft- and

essing and dissemination of spacecraft- and
aircratt-acquired images and photographs

and electronic data on the Earth's resources.
The Center also trains and assists users in the

application of suct data.
The EROS Data Cente

Landsat data, aerial photographss accuired by

tographs and other remotely sensed data ac-

quired by the National Aeronautics and Space

Administration (NASA), from research air-
craft, and from Skylab, Apoollo, and Gemin

spacecraft.
Orders tor photographs and images, inquir-
ies on the availability of coverage over specific

areas, and requests for price information

should be directed to:
EROS Data Cen

U.S. Geotlogical Survey
SSoux Falls SD 57709

Sioux Falls, SD 57198
Phone: (605) 594-6511, Ext. 151

FTS: $784-7151$
At the hert of the

computer complex that controls a data base of

政 the Earth's surfa inages and photographs

pecific geographic areas of interest, and

serves as a management tool for the entire

data reproduction process. The computerized
data storage and retrieval system is based on a
geographic system of latitude and longitude.

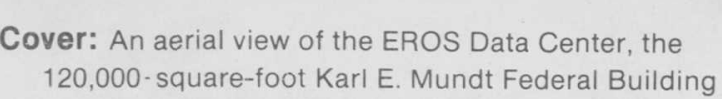

supplemented by information about image
quality, cloud cover, and type of data. Guided
by customer requirements, the computer will ich the requester can make a tinal Periodically, training sessions in remote
Pest Normally, the sessions are less than 1 week
long and stress the use of data for a prtic application, such as agriculturat inventory or water management. About twice a year, a 4-
week course is offered for foreign nationat This course stresses the fundamentals of remote sensing and introduces the application various natural resource management pro Iems. Formal training is also supplemented the basic methodology of remote sensing and selected applications capability to perform cor has an expanding ysis of images. Special devices permit the niques to classify phenomena by their reflactance or emittance in different parts of the
electromagnetic

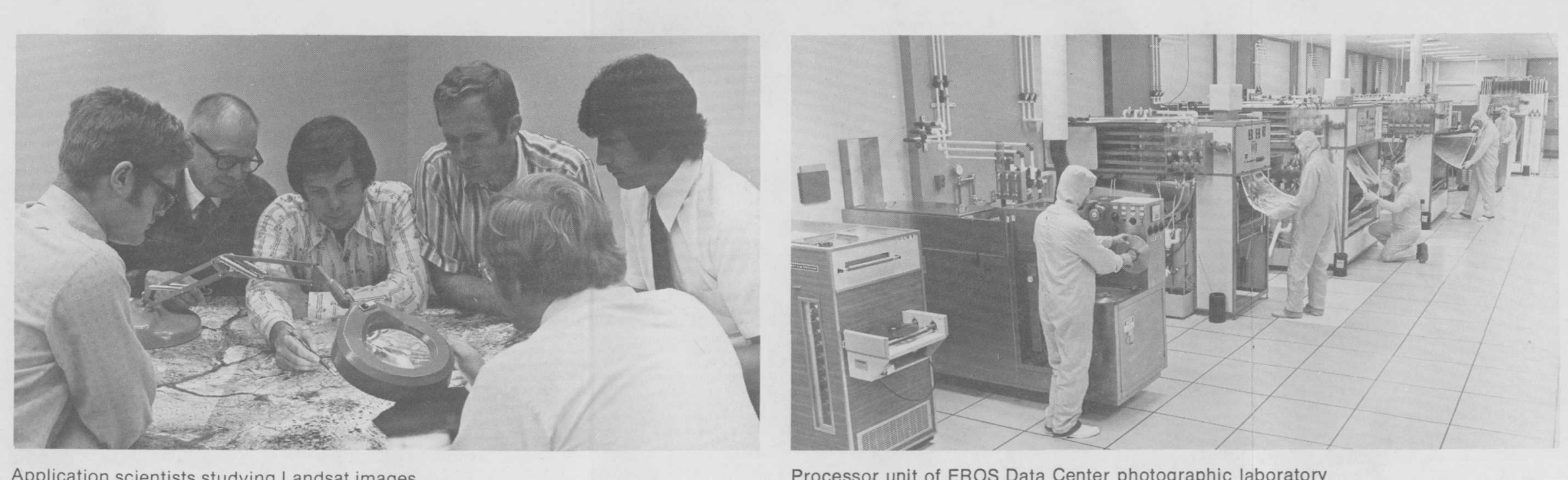
age of almost the entire globe. Datat transmit
May 1973. The manned missions to the speace vehicle were launched
November 16,1973 .
The spacecraft trav Landsat Data

NASA's Landsat satellites are unmanned
space observatories orbiting the Earth at an
altitude of approximately 570 miles 5920 kitit altitude of approximately 570 miles 2920 kil-
ometers $(\mathrm{km})$ ). Each Landsat circles the Earth every 103 minutes and repeats its orbital path are subsequently sent to the EROS Data Cen-
and ler through the NASA Goddard Space Flight
Center in Greenbelt, Md., via a domestic cormverted to photograph-like images and compuler compatible tapes at the Data Center. Each statute miles ( 185 by $185 \mathrm{~km}$ ). Copies are stored at the EROS Data Center for reproduc-

Skylab Data $0-2$ and RB-57F aircraft at altitudes above
60,000 feet $[18,000$ meters (m)].
Aerial photographs are available in black graphs, images, and other data of selected data were collected over test sites selected to

NASA Aerial Photog NASA aerial photographs are the product sources Aircraft Program. The program pritechniques in aerial flights, generally over preselected test sites within the continental Photographs available in a wide variety of
formats were obtained from standard aircraft at altitudes of a few thousand feet up and from Aerral photographs are available in black
and white, coolor, or false-color intrared. Because these data are accuuired at trelativively low
altitudes ground features such as roads.
[1]

skylab Spacecraft

NASA U-2 airplaa

farms, and cities are easily identifiable. Elec-
tronic data trom the more sophisticated research sensors on the aircraft may als
obtained through the Data Center.

Aerial Mapping Photographs

For the past 25 years, aerial photographs
have been acquired by the U.S. Geoological
Survey and ng the United States. Tha detas anges from 2,000 to 40,000 feet 6000 to 12,000 m), depending on the planned use of the pho-
Visits, Tours, and News Media Inquiries The visitiors' lobby of the EROS Data Center
is open to the public from 8 a.m. to $4: 15$ p.m.
. Saturdays. Pictorial exhibits and photographic displays are in the lobby aread Guided tours
and film presentations for individuals and small groups are offered on weekdays at 10:30
a.m. and 2 p.m. Guided tours and educational for unper en pertary school high school, and college groups, and tor service clubs and news media.
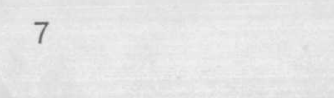


\section{EROS Office}

Within the technology of the space age lies a key to increased knowledge about the resources and environment of the Earth. This key is remote sensing-detecting the nature of an object without actually touching it. Although the photographic camera is the most familiar remote-sensing device, other instrument systems, such as scanning radiometers and radar, can produce photographs and images.

On the basis of the potential of this techno!ogy, and in response to the critical need for greater knowledge of the Earth and its resources, the Department of the Interior established the EROS Office to gather and use remotely sensed data collected by satellite and aircraft of natural and man-made features on the Earth's surface.

The potential application of remote-sensing techniques for inventory and management of the Nation's Earth resources and monitoring of the environment has been demonstrated in many ways. Landsat images, because of their synoptic coverage, have been used to identify previously unmapped geologic structures as targets for exploration for oil, gas, copper, and other minerals and are being used to inventory water impoundment areas. The repetitive coverage of satellite data provides information for land-use planning with a timeliness not previously possible. The capability of detecting changes in land use has proven effective in monitoring strip mining and reclamation of strip mines and is useful for gaging the environmental impact of the Alaskan pipeline. Satellite data are also used for evaluating range conditions over vast areas of the Western United States and for updating small-scale maps.

In addition to meeting the needs of the Department of the Interior, the EROS Office has the responsibility for providing copies of remotely sensed data in response to public demand and for providing user training and assistance to further the understanding and use of remotely sensed data.

\section{National Cartographic Information Center}

The National Cartographic Information Center $(\mathrm{NClC})$ is headquartered in the Geological Survey's National Center in Reston, Va. It provides a unique service to those customers requiring information on the availability of cartographic data, including multiuse maps, geodetic control, aerial photographs, and space images. Qualified personnel in the fields of geodesy, photogrammetry, photography, and cartography are ready to help those with specialized needs.

The EROS Data Center functions as an integral part of the NCIC system for those requesting information about available aircraft or space imagery and for those wanting to place orders for these data. This service is readily available by a direct terminal link to the Data Center's computerized data base. Inquiries and orders for data are transmitted daily from NCIC to the EROS Data Center to provide a timely response to customer needs.

This publication is one of a series of general interest publications prepared by the U.S. Geological Survey to provide information about the earth sciences, natural resources, and the environment. To obtain a catalog of additional titles in the series "Popular Publications of the U.S. Geological Survey," write:

Branch of Distribution or U.S. Geological Survey 604 South Pickett Street Branch of Distribution U.S. Geslogical Survey Box 25286, Federal Center Alexandria, VA 22304 Denver, CO 80225 
The EROS Data Center is located on a 318-acre tract approximately 16 miles northeast of Sioux Falls, South Dakota. Privately owned or rental cars are needed for travel to and from the center. There is no scheduled transportation from Sioux Falls.

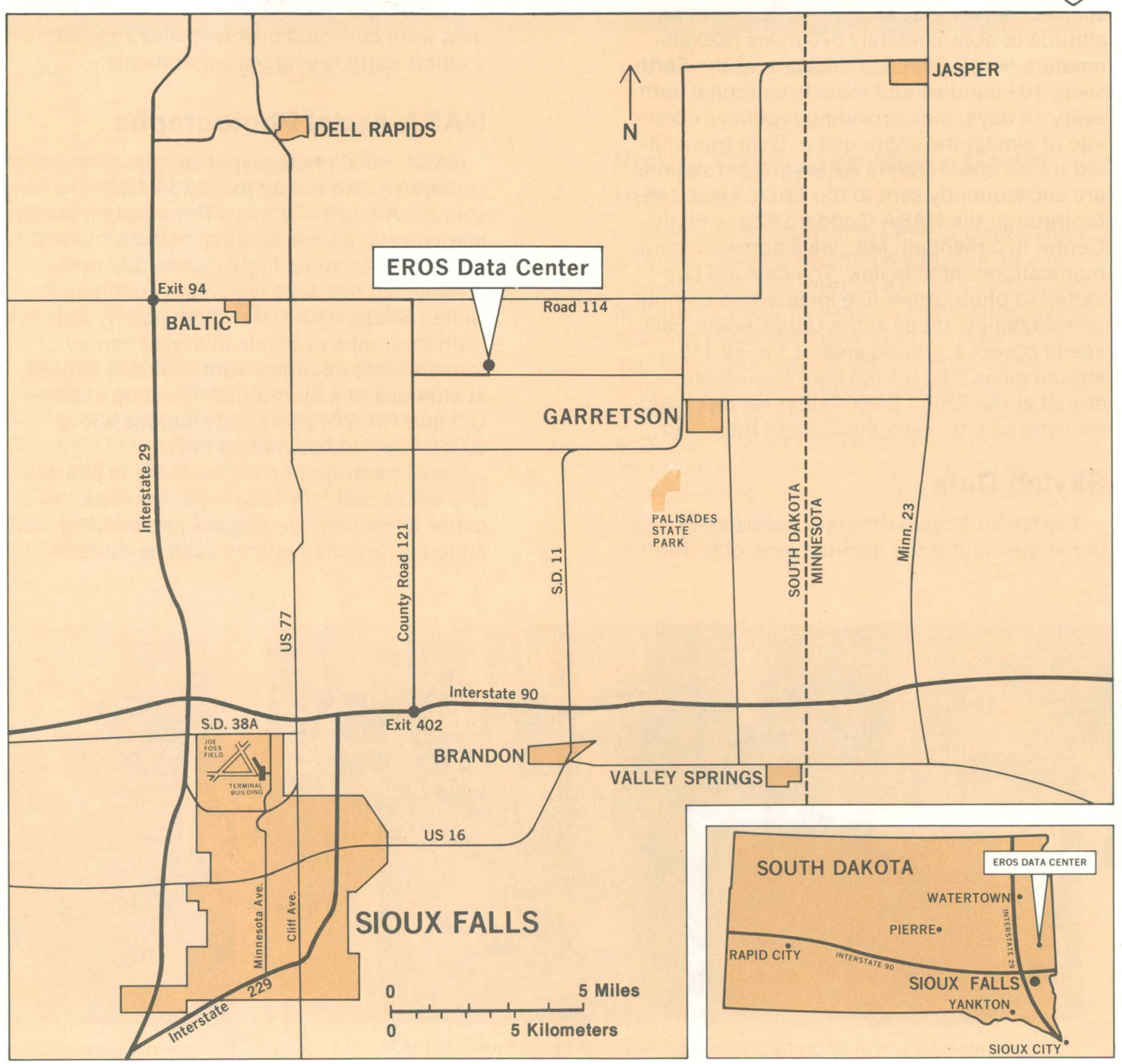

